\title{
THE IMPACT OF BIO FUELS PRODUCTION IN THE WORLD ON THE PRICES OF EGYPTIAN IMPORTS OF FOOD COMMODITIES
}

\author{
BADR, 0. A. , W. A. FARRAG AND \\ NAGLAA EL-SAID AHMED SHABAN
}

Agricultural Economics Research Institute, ARC, Dokki, Giza.

(Manuscript received 3 July 2018)

\begin{abstract}
he natural sources of energy such as oil, coal and all other fossil fuels, bio fuels is

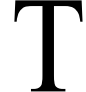
defined as an energy that derived from living organisms, whether plant or animal, the production of bio fuels is consumed with about, and about $9 \%$ of the quantity produced of the oils to produce biodiesel, which will rise to $20 \%$ by 2018 . And that $2 \%$ of the total area of crops in the world, used in the production of bio fuels will rise to $4 \%$ by 2030 . The study problem can be summarized of the rise in petroleum prices from $\$ 49$ a barrel in 2000 to 146 dollars in 2015, and are the major countries trying to extend its influence on the Middle East states that producing petroleum during internal conflicts of these States, as well as to the orientation of the major countries to produce bio-fuel from plant oils, which leads to a lack of world supply, which had a negative impact on the imported states of the plant oil crops in raising the prices of plant oil crops. The study aims to identify the impact of bio fuels production in the world on import prices of Egypt from strategic food commodities from plant oil. As for the development of self-sufficiency ratio of plant oil it decline significant statistically of about $10.04 \%$ of the average period of about $45.8 \%$ as the local global, price and the import price for plant oils they are an increase significant statistically by about $4.1 \%, 5.8 \%$ and $9.5 \%$ respectively of the average study period of about 553, 910, 1658 dollar/ton. Study of the impact of the world price of a barrel of oil, the net amount of the global biodiesel produced the total elasticity to the function reached about 1.56 , that is, an increase of the world price of a barrel of oil, $10 \%$ would lead to an increase in the biodiesel production with $15.6 \%$. The study showed that the quantity world biodiesel plant oil, of the most important factors affecting the Egypt important prices the total elasticity reached about 0.25 , that is, an increase in the net amount of biodiesel produced by $10 \%$, will lead to an increase in the world price of plant oil by $2.5 \%$ during the study period . Studying the impact of the quantity of world production of biodiesel on the import price of plant oils, the total elasticity of function reached about 0.41 , that is, an increase in the quantity of world production of biodiesel with $10 \%$, will lead to an increase in the import price of plant oils by $4.10 \%$ during the study period. The study showed that the most important factors affecting imports of plant oils in Egypt with increasing the quantity of domestic consumption by $10 \%$, will lead to an increase in the quantity of Egypt's imports of plant oils with about $7.9 \%$, and an increase in the quantity of world production of biodiesel, will lead to increase Egypt's imports of oils with about 5\% .
\end{abstract}

\section{RECOMMENDATIONS:}

The study recommends with:

1.It is necessary of the ministry of Agriculture to concentrate in its policy on raising the rate of self-sufficiency of plant oil crops.

2. It is must be working diversifying the sources of import markets, plant oil crop from throw studying the world markets or support the farmers to cultivating the oil crops

3. Studding the increasing of the domestic price per ton of oil crops to encourage the farmers to grow this crops to force the world increasing in prices.

4. Studding the possibility of cultivation the oil palm that could contribute in achieving the rate of self-sufficiency of the plant oil for Egypt.

5. Activation the application of the contract farming system for oil crops through cooperatives or agricultural development bank so as to ensure the farmers from marketing his crop. 


\title{
إنتاج الوقود الحيوي (الديزل) في العالم وأثره علي أسعار الواردات المصرية من الزيوت النباتية
}

\author{
عمر أحمد بدر ، وجيه عبد العزيز فراج ، نجلاء السيد أحمد شعبان

$$
\text { معهد بحوث الاقتصاد الزراعي - مركز البحوث الزراعية - الدقي - الجيزة. }
$$

مقدمة

يعد الوقود الحيوي أحد أهم مصادر الطاقة المتجددة والتي تختلف عــن مصـــادر الطاقـــة الطبيعية منل النفط و الفحم الحجرى وكافة أنواع الوقود الإحفورى و الوقود النووي ، و الوقود الحيوي

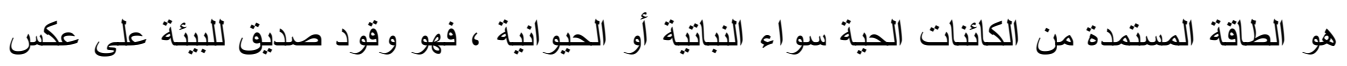
الوقود الإحفورى كما يعتبر الوقود الحيوي من الموارد المتجددة ، وهو من الناحية النظرية خال من

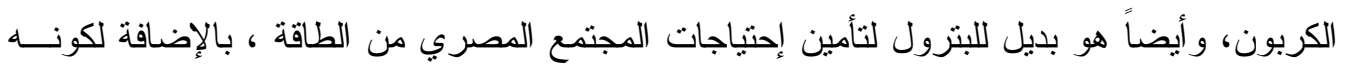

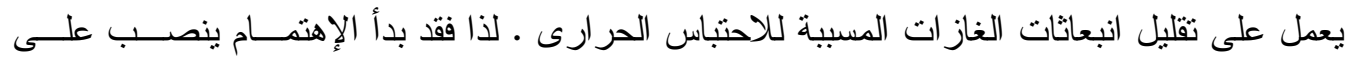

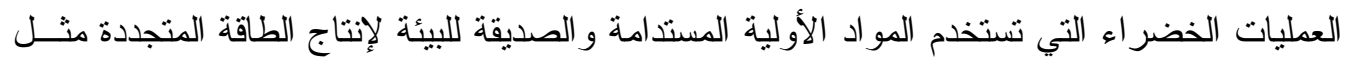

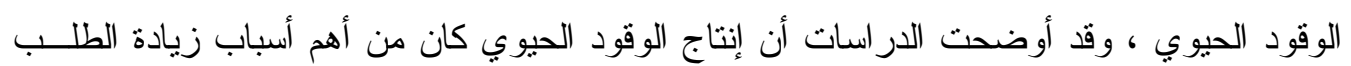

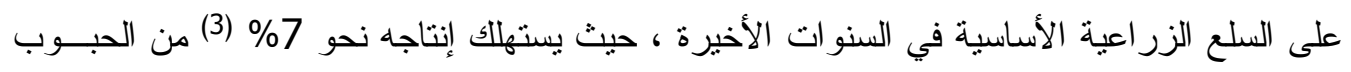

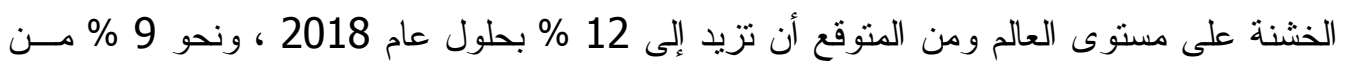

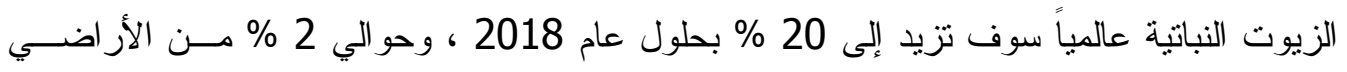

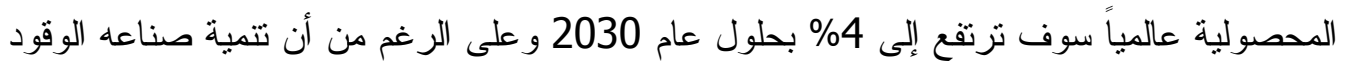

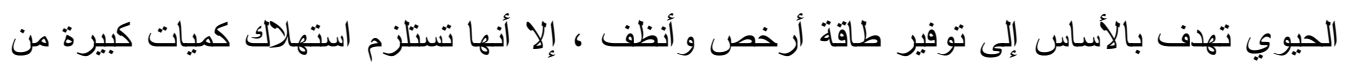

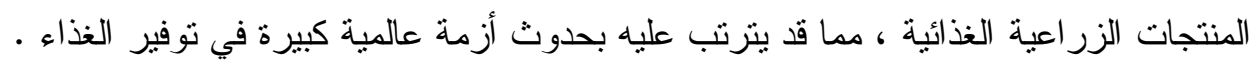

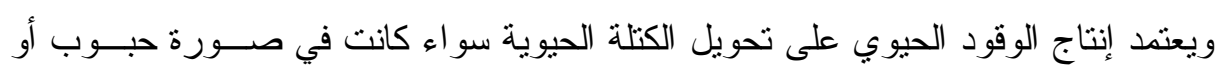

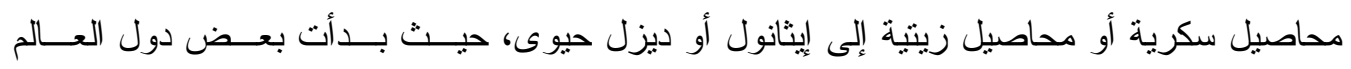

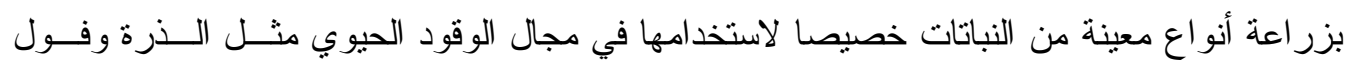

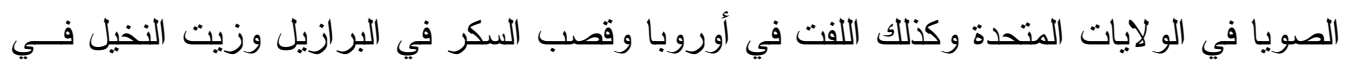

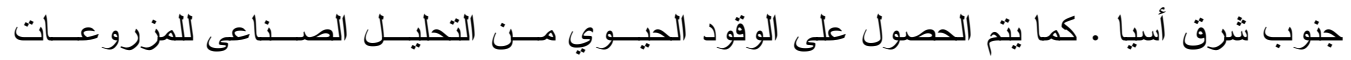

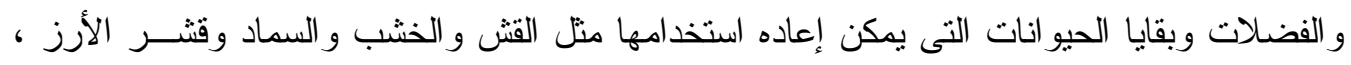

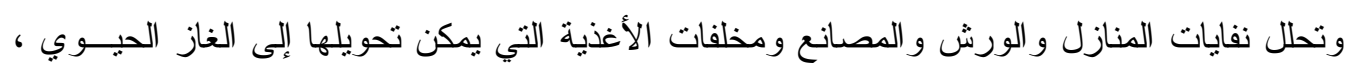

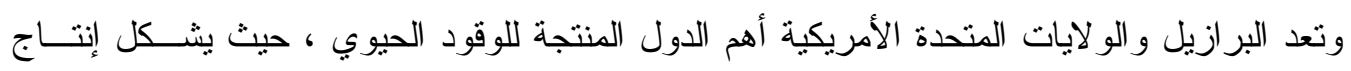
الدولتان حو الي 90\% من الإنتاج العالمي . 


\section{مشكلة البحث}

تكمن مشكلة الدر اسة في توجه أكبر دول العالم وفى مقدمتها الو لايات المتحـــدة الأمريكيــة

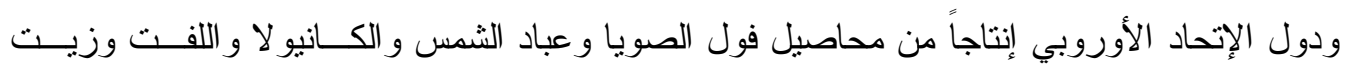

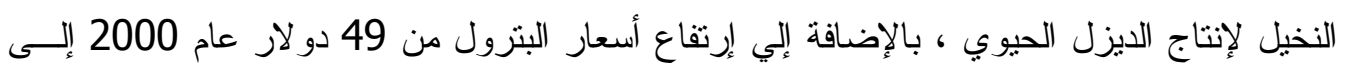

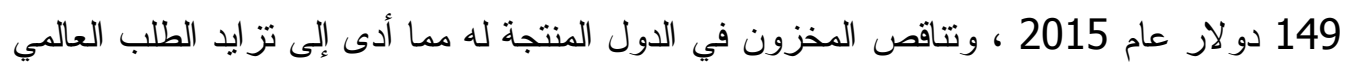

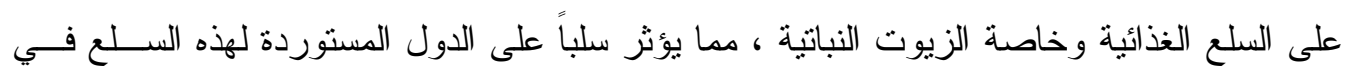
إرتقاع أسعار الواردات من السلع الغذائية الإستر اتيجية (الزيوت النيه ، النباتية).

\section{الأهذف من البحث}

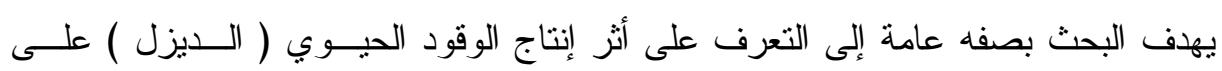

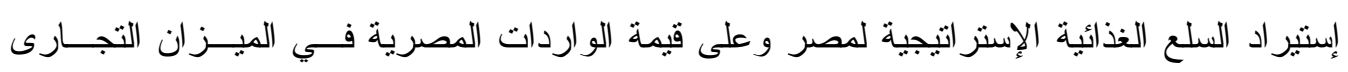

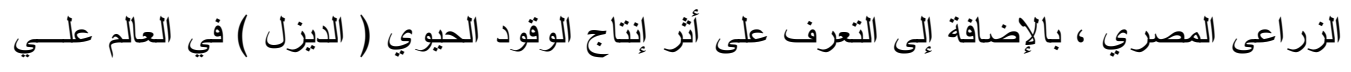

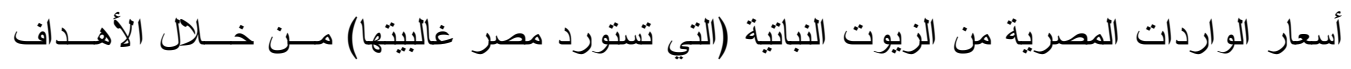
الفرعية التالية: - 20 - n

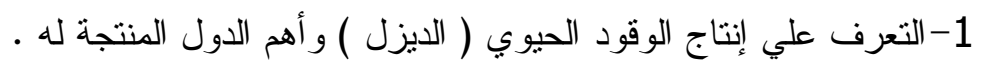

2-نظور الكميات المنتجة من الوقود الحيوي (الديزل) خلال فترة الدراسة خلال الفترة (2000. 2016

3-أهم المحاصيل الزر اعية المستخدمة في إنتاج الوقود الحيوي ( الديزل ) و أسعار ها العالمية.

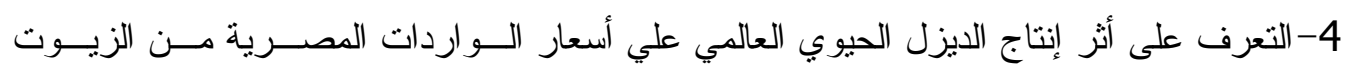

\section{النباتية.}

\section{الأسلوب البحثى ومصادر البيانات}

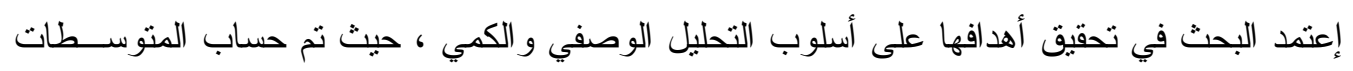

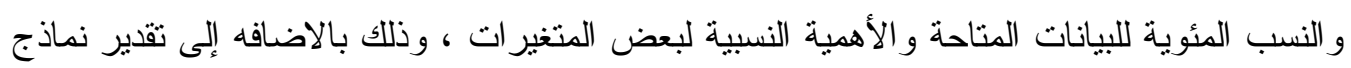

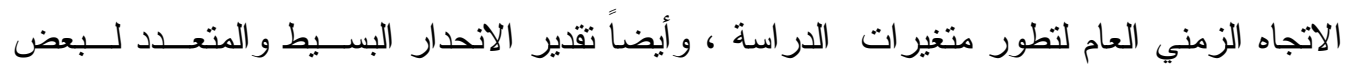

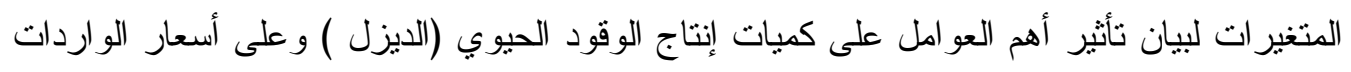
المصرية من السلع الغذائية. و اعتمد البحث على البيانات المنشورة في الكتاب الإحصائي السنوي للجهاز المركزي للتعبئة العامــة

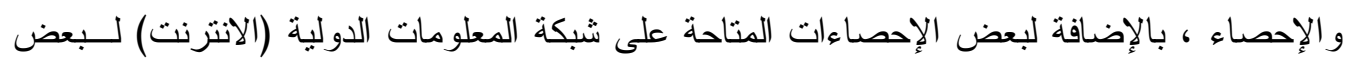

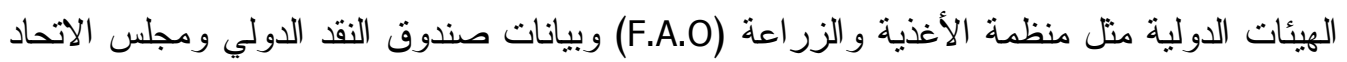

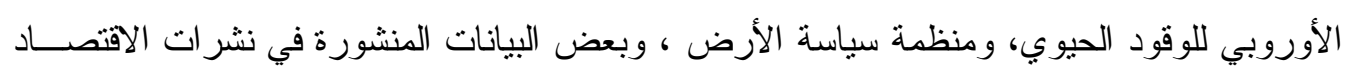

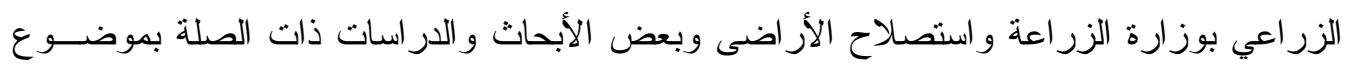




$$
\text { - إنتاج الوقود الحيوي (الديزل) في العالم }
$$

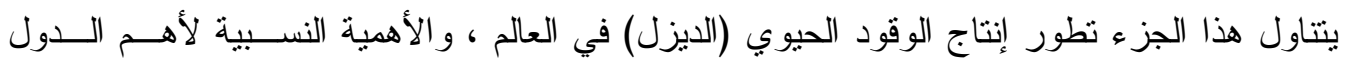
المنتجة له و أهم العو امل المؤثرة علي إنتاج الديزل الحيوي في العالم ، بالإضافة إلي در اســـة الآتـار

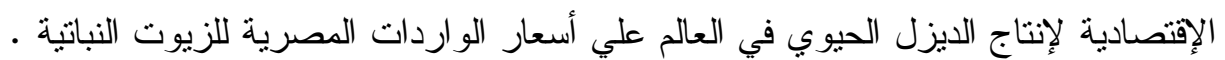

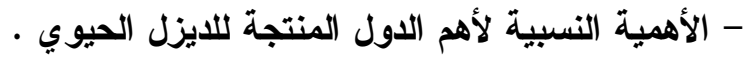

$$
\text { 1 - 1 }
$$

بدر اسة البيانات الواردة بالجدول رقم (1) تبين أن الإنتاج العالمي من الديزل الحيوي يتر اوح ما بـين

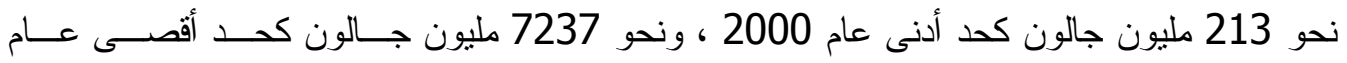

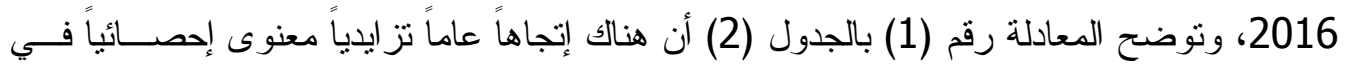

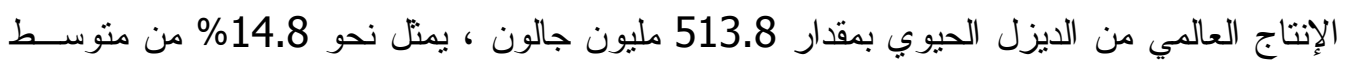
الإنتاج العالمي من الديزل الحيوي البالغ نحو 3468.4 مليون جالون خلال فترة الدراســة (2000-

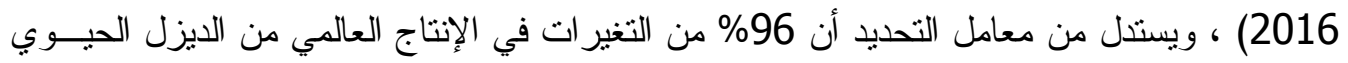
تعزى إلى التغيرات في العو امل التى يعكسها متغير عنصر الزمن و الباقي يرجع إلي عو امــلـ غيــر

\section{2-}

يبين جدول رقم (1) أن إنتاج الاتحاد الأوروبي من الديزل الحيوي يتز اوح مابين نحو 209 مليــون

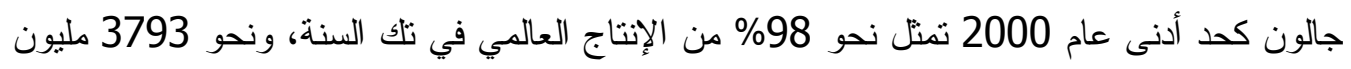

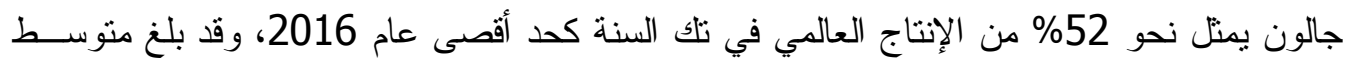

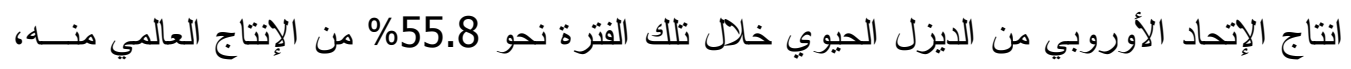
ويتضح من المعادلة رقم (2) بالجدول (2) أن هناك إتجاهاً عاماً تز ايدياً معنوى إحصائياً فــي إنتــاج

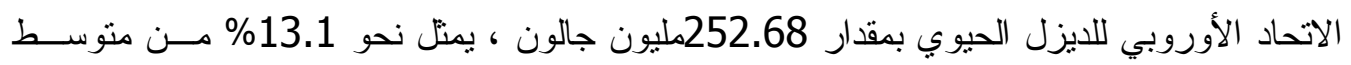

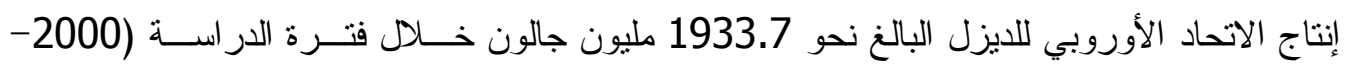
2016) ، ويستدل من معامل التحديد أن نحو 98\% من التغير ات في إنتاج الاتحاد الأوروبي للايزل

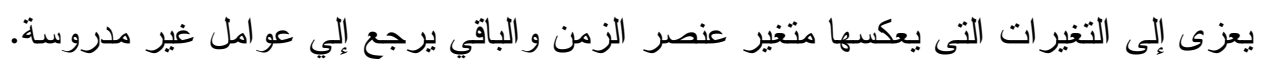

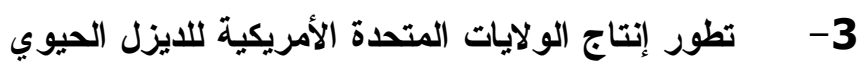

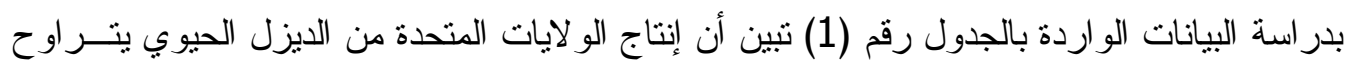

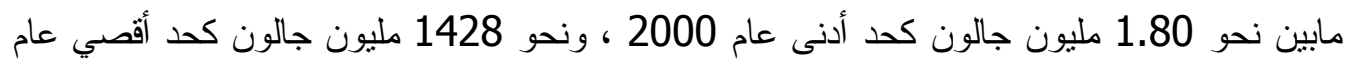

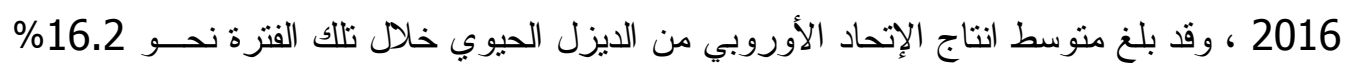

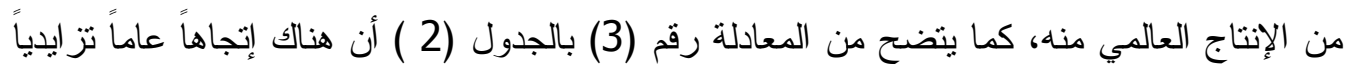

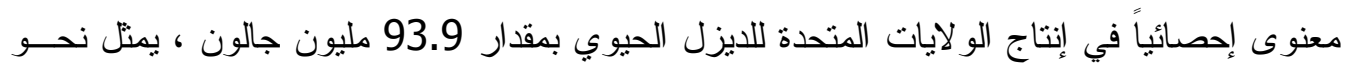

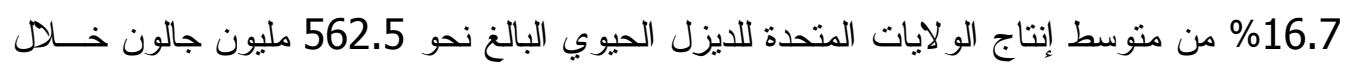

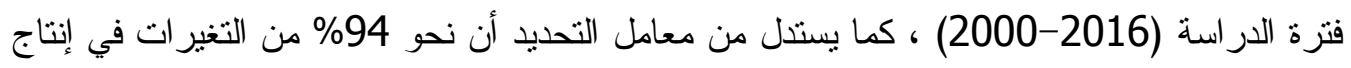


الديزل الحيوي بالو لايات المتحدة الأمريكية إنما تعزى إلى التغير ات التى يعكســـا متغيـر عنصـر الزمن و الباقي برجع إلي عو امل غير مدروسة.

جدول رقم (1): الأهمية النسبية لأهم الدول المنتجة للايزل الحيوي خلا الفترة (2016-2000)

\begin{tabular}{|c|c|c|c|c|c|c|c|}
\hline ا العالمتاج & إلتاج باقي دول العالم من & ا العالمي & إلإنتاج الولايات & ا العالميتاج & الألتاج الاتحاد & الإلتاج العالمي & البيان \\
\hline 1.0 & 2.2 & 0.8 & 1.8 & 98 & 209.0 & 213.0 & 2000 \\
\hline 1.9 & 5.0 & 1.9 & 5.0 & 96 & 255.0 & 265.0 & 2001 \\
\hline 1.3 & 5.0 & 3.9 & 15.0 & 95 & 363.0 & 383.0 & 2002 \\
\hline 0.8 & 4.0 & 3.9 & 20.0 & 95 & 485.0 & 509.0 & 2003 \\
\hline 1.1 & 6.8 & 6.1 & 37.2 & 93 & 570.0 & 614.0 & 2004 \\
\hline 5.4 & 55.3 & 11.4 & 117.7 & 83 & 859.0 & 1032.0 & 2005 \\
\hline 8.7 & 154.8 & 13.8 & 246.2 & 78 & 1378.0 & 1779.0 & 2006 \\
\hline 16.2 & 433.4 & 19.1 & 510.6 & 65 & 1735.0 & 2679.0 & 2007 \\
\hline 25.8 & 1059.3 & 19.7 & 808.7 & 55 & 2242.0 & 4110.0 & 2008 \\
\hline 33.3 & 1460.6 & 12.8 & 561.4 & 54 & 2368.0 & 4390.0 & 2009 \\
\hline 38.4 & 2017.5 & 14.3 & 750.5 & 47 & 2485.0 & 5253.0 & 2010 \\
\hline 30.6 & 1567.2 & 15.6 & 799.8 & 54 & 2747.0 & 5114.0 & 2011 \\
\hline 31.0 & 1750.4 & 15.7 & 886.6 & 53 & 3008.0 & 5645.0 & 2012 \\
\hline 31.3 & 1932.7 & 15.8 & 973.3 & 53 & 3270.0 & 6176.0 & 2013 \\
\hline 31.5 & 2115.0 & 15.8 & 1060.0 & 53 & 3532.0 & 6707.0 & 2014 \\
\hline 28.4 & 1944.0 & 19.6 & 1341.0 & 52 & 3572.0 & 6857.0 & 2015 \\
\hline 27.9 & 2016.0 & 19.7 & 1428.0 & 52 & 3793.0 & 7237.0 & 2016 \\
\hline 28.0 & 972.3 & 16.2 & 562.5 & 55.8 & 1933.6 & 3468.4 & المتوسط \\
\hline
\end{tabular}

المصدر: جمعت وحسبت من الموقع الاككتروني لمنظمة سياسة الأرض، www.earth_policy.org

جدول رقم (2) : معادلات الاتجاه العام لأهم الدول المنتجة للايزل الحيوي خلا الفترة (2016-2000) الكمية: بالمليون جالون

\begin{tabular}{|c|c|c|c|c|c|}
\hline $\mathbf{R}^{2}$ & معدل التغير & متوسط الفترة & المعادلة & 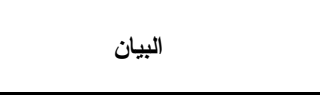 & 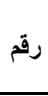 \\
\hline 0.961 & 14.8 & 3468.4 & $\begin{array}{l}\hat{y}=-1156.09 \\
+513.83 X_{i} \\
(19.225)^{* *}\end{array}$ & الإتتاج العالمي من الديزل الحيوي & 1 \\
\hline 0.979 & 13.1 & 1933.6 & $\begin{array}{l}\hat{y}=-340.52+252.68 x_{i} \\
(26.500)^{* *}\end{array}$ & إنتاج الاتحاد الأوروبي من الديزل & 2 \\
\hline 0.940 & 16.7 & 562.5 & $\begin{array}{l}\hat{y}=-282.37+93.88 x_{i} \\
(15.349)^{* *}\end{array}$ & إنتاج الولايات المتحدة من الديزل & 3 \\
\hline 0.875 & 17.2 & 972.3 & $\begin{array}{l}\hat{y}=-533.20+167.28 x_{i} \\
(10.267)^{* *}\end{array}$ & إنتاج باقي دول العالم من الديزل & 4 \\
\hline
\end{tabular}

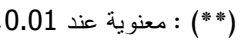

حيث أن : y : تثير إلى الإنتاج العالمي التقديري من الديزل الحيوي لكل من الاتحاد الاوربى و الو لايات المتحدة الأمريكية وباقي دول العالم على الترتيب

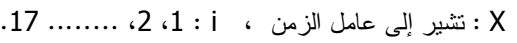

المصدر: حسبت من جدول رقم (1). 

أتضح من بيانات جدول رقم (1) أن إنتاج باقي دول العالم من الديزل الحيوي يتراوح مـــابين نحسو

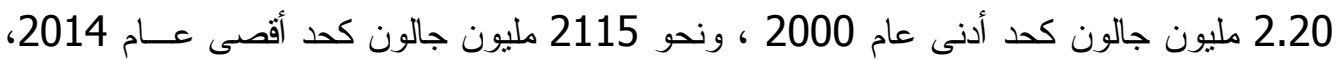

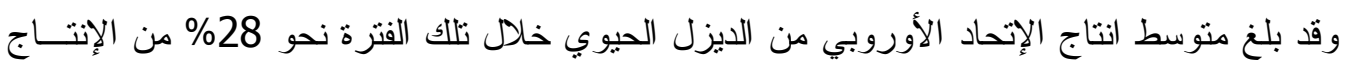

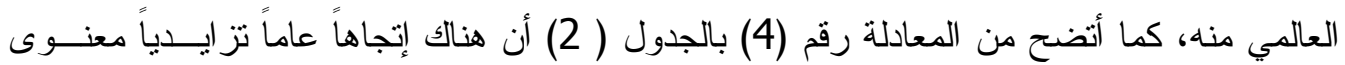

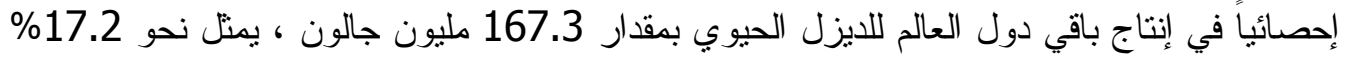

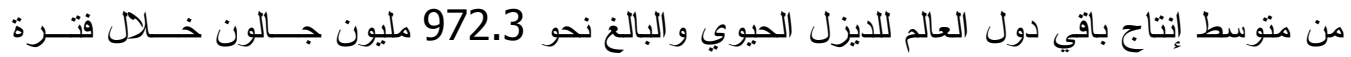

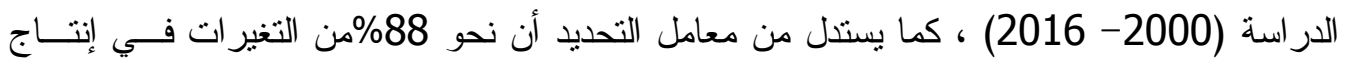
الديزل الحيوي بباقي دول العالم إنما تعزى إلى التغير ات التى يعكسها متغير عنصر الزمن و البـاقي برجع إلي عو امل غير مقيسه.

\section{- تطور الإتتاج العالمي واستهلاك وواردات مصر من الزيوت النباتية.}

\section{1 - تطور الإتتاج العالمى من الزيوت النباتية}

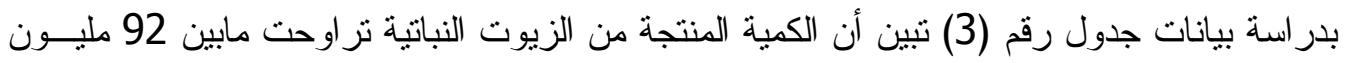
طن كحد أدنى عام 2000 ، ونحو 196 مليون طن كحد أقصى عام 2016 ، ويتضـح من المعادلــــة

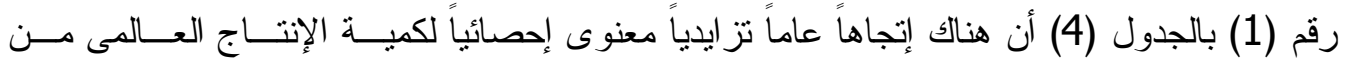

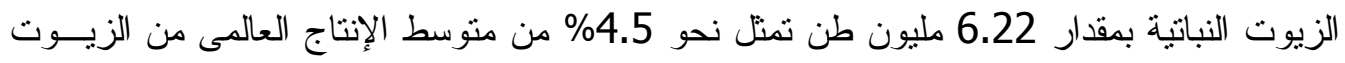

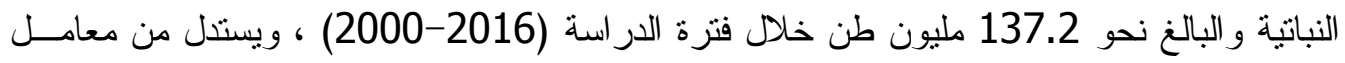

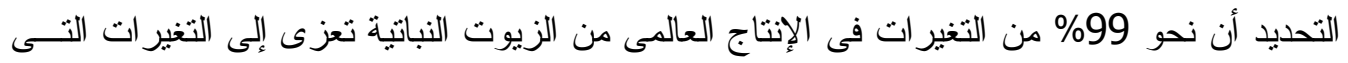

$$
\text { 2-2 تعكسها متغير عنصر الزمن و الباقي برجع إلي عو امل غير مقيسه. }
$$

توضح بيانات جدول رقم (3) أن كمية المعروض العالمى من الزيوت النباتية نز اوحت مـــابين نحسـو

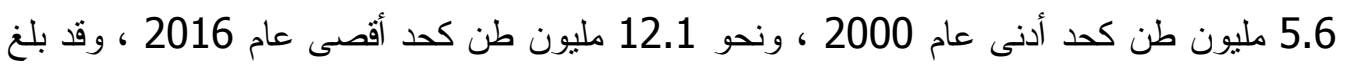

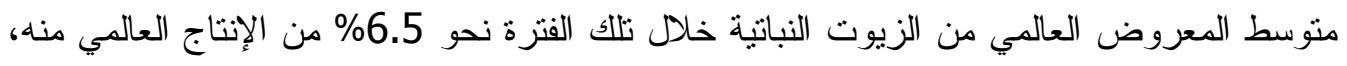

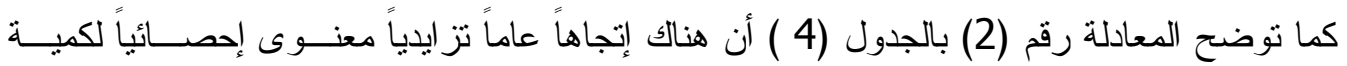

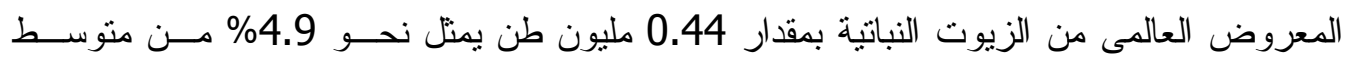
المعروض العالمى من الزيوت النباتية و البالغ نحو 8.9 مليون طن خلال فتــرة الدر اســـة (2000-

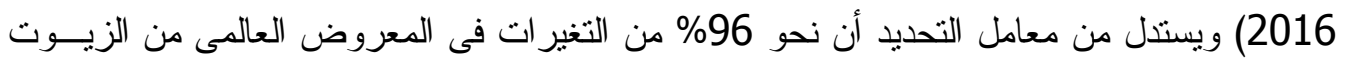

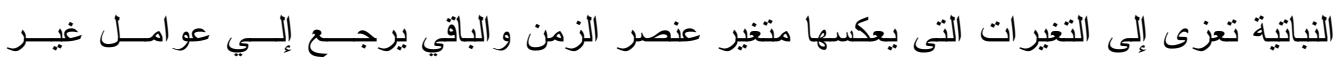
مدروسة.

3- تطور واردات مصر من الزيوت النباتية . .

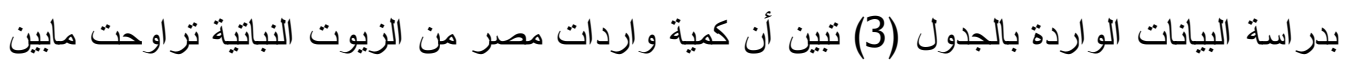

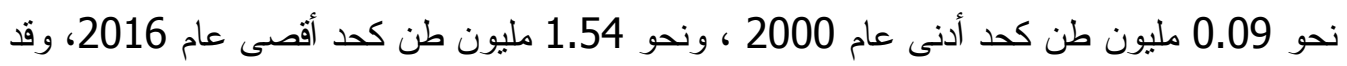

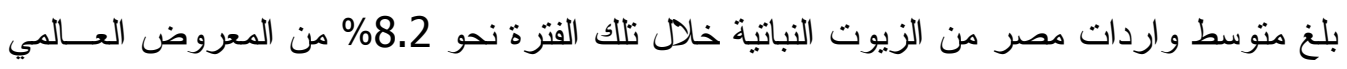


منها، كما يتضح من المعادلة رقم (3) بالجدول (4 ) أن هنالك إتجاهاً عاماً تز ايدياً معنوى إحصــائياً

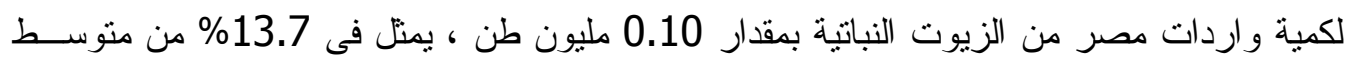

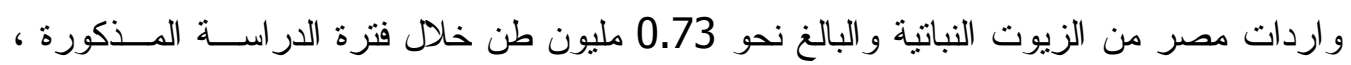

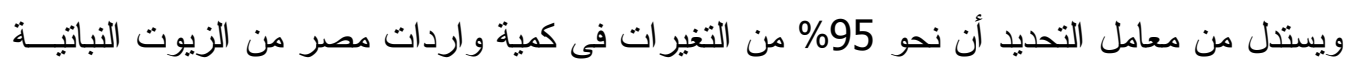

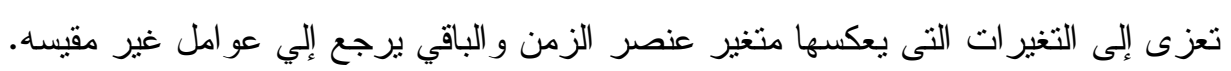
4- تطور الإنتاج المحلى من الزيوت النباتية

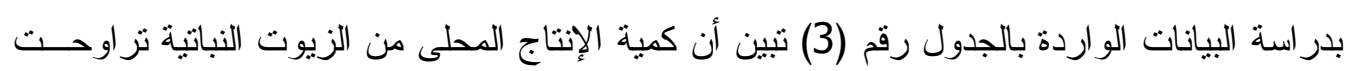
مابين نحو 0.32 مليون طن كحد أدنى عام 2007، ونحو 0.50 مليون طن كحد أقصى عام 2006

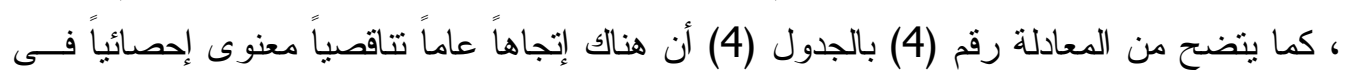

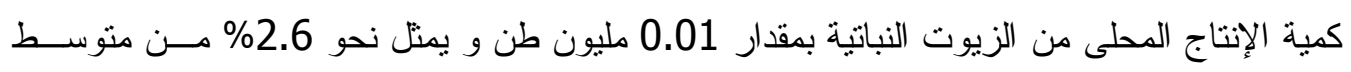

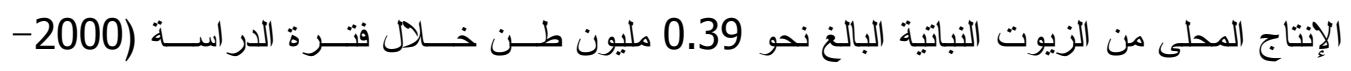

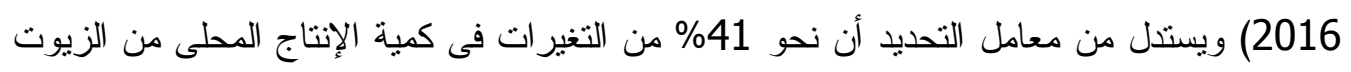
النباتية تعزى إلى التغيرات التى يعكسها متغير عنصر الزمن و الباقي يرجع إلي عو امل غير مقيسه.

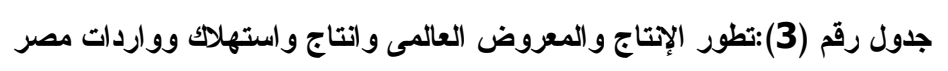

من الزيوت النباتية خلا الفترة (2016) (2000)

(كمية الديزل بالمليون جالون ، كمية الإنتاج من الزيوت: بالمليون طن) (2000-2016 )

\begin{tabular}{|c|c|c|c|c|c|c|c|c|}
\hline الأاتى \% ألفاء & الاستهلاك من الزيوت & 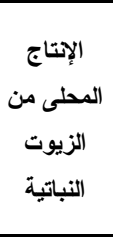 & 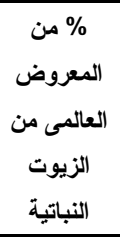 & مصر من & العالمى من المعروض & 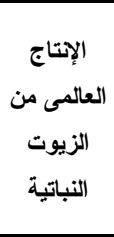 & العالمى من الإتتاج & البيان \\
\hline 84.5 & 0.58 & 0.49 & 1.6 & 0.09 & 5.6 & 92.0 & 213.0 & 2000 \\
\hline 76.8 & 0.56 & 0.43 & 2.3 & 0.13 & 5.6 & 95.0 & 265.0 & 2001 \\
\hline 75.0 & 0.48 & 0.36 & 1.7 & 0.10 & 6.0 & 98.0 & 383.0 & 2002 \\
\hline 80.9 & 0.47 & 0.38 & 1.6 & 0.10 & 6.2 & 105.0 & 509.0 & 2003 \\
\hline 89.8 & 0.47 & 0.42 & 3.9 & 0.29 & 7.4 & 111.0 & 614.0 & 2004 \\
\hline 60.0 & 0.70 & 0.42 & 3.8 & 0.29 & 7.7 & 121.0 & 1032.0 & 2005 \\
\hline 43.5 & 1.15 & 0.50 & 7.9 & 0.66 & 8.4 & 127.0 & 1779.0 & 2006 \\
\hline 26.7 & 1.2 & 0.32 & 10.9 & 0.88 & 8.1 & 131.0 & 2679.0 & 2007 \\
\hline 33.6 & 1.13 & 0.38 & 7.5 & 0.76 & 10.2 & 136.0 & 4110.0 & 2008 \\
\hline 35.1 & 1.14 & 0.40 & 8.8 & 0.80 & 9.1 & 142.0 & 4390.0 & 2009 \\
\hline 33.0 & 1.12 & 0.37 & 8.6 & 0.78 & 9.1 & 146.0 & 5253.0 & 2010 \\
\hline 28.0 & 1.32 & 0.37 & 9.6 & 0.99 & 10.3 & 153.0 & 5114.0 & 2011 \\
\hline 25.7 & 1.40 & 0.36 & 10.1 & 1.08 & 10.7 & 159.0 & 5645.0 & 2012 \\
\hline 24.3 & 1.48 & 0.36 & 10.5 & 1.17 & 11.1 & 165.0 & 6176.0 & 2013 \\
\hline 22.4 & 1.56 & 0.35 & 10.9 & 1.27 & 11.6 & 171.0 & 6707.0 & 2014 \\
\hline 20.6 & 1.65 & 0.34 & 12.2 & 1.45 & 11.9 & 185.0 & 6857.0 & 2015 \\
\hline 19.5 & 1.69 & 0.33 & 12.7 & 1.54 & 12.1 & 196.0 & 7237.0 & 2016 \\
\hline 45.8 & 1.06 & 0.39 & 8.2 & 0.73 & 8.9 & 137.2 & 3468.4 & المتوسط \\
\hline
\end{tabular}

المصدر: جمعت وحسبت من الموقع الاكتروني لمنظمة سياسة الأرض، 


\section{5- تطور الإستهلاك المحلى من الزيوت النباتية}

ويتضح من بيانات جدول رقم (3) أن كمية الإستهالاك المحلى من الزيوت النباتية نز اوحـــ مــابين نحو 0.47 مليون طن كحد أدنى عامي (2004-2003)، ونحو 1.69 مليون طن كحد أقصى عام

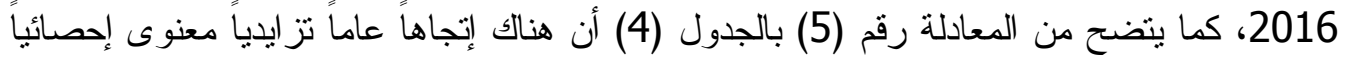
فى كمية الاستهلاك المحلى من الزيوت النباتية بمقدار 0.08 مليون طن يمثـل نحـو 7.5\% مــن متوسط الاستهلالك المحلى من الزيوت النباتية البالغ نحو 1.06 مليون طن خــلال فتــرة الدر اســـة المذكورة ، ويستدل من معامل التحديد أن نحو 91\% من التغيرات فى كمية الاستهلاك المحلى مسن الزيوت النباتية إنما تعزى إلى التغير ات التى يعكسها متغير عنصر الزمن و الباقي يرجع إلي عو امــل فيل

6- تطور الاكتفاء الذاتى من الزيوت النباتية .

وبدر اسة نسبة الإكتفاء الذاتى من الزيوت النباتية بالجدول رقم (3) يتضح أن نلك النسبة قد نز اوحت مابين نحو 19.5\% كحد أدنى عام 2016، ونحو 89.8\% كحد أقصى عام 2004 ، كما يتضح من المعادلة رقم (6) بالجدول (4) أن هناك إتجاهاً عاماً تناقصياً معنوى إحصائياً فى نسبة الاكتفاء الذاتى من الزيوت النباتية بنحو 4.6\% تمنل نحو 10.04\% من منوسط نسبة الاكتفاء الذاتى من الزيوت لهن

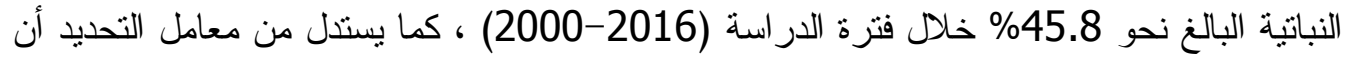
82 من التغيرات فى نسبة الاكتقاء الذاتى من الزيوت النباتية تعزى إلى التغيرات التى يعكسها

$$
\text { متغير عنصر الزمن و الباقي يرجع إلي عو امل غير مدروسة. }
$$

جدول رقم (4) : معادلات الاججاه العام لتطور الإتاج و المعروض العالمى وواردات مصر و الإتاج المحلى والاستهلاك المحلى ونسبة الاكثفاء الذاتى من الزيوت النباتية خلا الفترة (2016-2000)

\begin{tabular}{|c|c|c|c|c|c|}
\hline $\mathbf{R}^{2}$ & $\begin{array}{l}\text { معدل التغير } \\
\text { السنوى }\end{array}$ & متوسط الفترة & المعادلة & 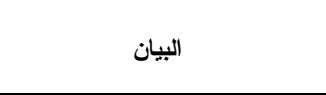 & 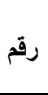 \\
\hline 0.988 & 4.5 & 137.2 & $\begin{array}{r}\hat{y}=81.27+6.22 X_{i} \\
(34.601)^{* *}\end{array}$ & الإتاج العالمى من الزيوت النباتية & 1 \\
\hline 0.962 & 4.9 & 8.9 & $\begin{aligned} \hat{y}=4.97+ & 0.44 X_{i} \\
& (19.374)^{* *}\end{aligned}$ & النباتية المعروض العالمى من الزيوت & 2 \\
\hline 0.953 & 13.7 & 0.73 & $\begin{array}{r}\hat{y}=-0.12+0.10 X_{i} \\
(17.531)^{* *}\end{array}$ & واردات مصر من الزيوت النباتية & 3 \\
\hline 0.409 & -2.6 & 0.39 & $\begin{aligned} & \hat{y}=0.45- 0.01 X_{i} \\
&(-3.223)^{* *}\end{aligned}$ & الإتتاج المحلى من الزيوت النباتية & 4 \\
\hline 0.905 & 7.5 & 1.06 & $\begin{array}{r}\hat{y}=0.33+0.08 X_{i} \\
(11.952)^{* *}\end{array}$ & الإنبتهلاك المحلى من الزيوت & 5 \\
\hline 0.820 & -10.04 & 45.8 & $\begin{array}{r}\hat{y}=87.25-4.60 X_{i} \\
(-8.256)^{* *}\end{array}$ & الإكتفاء الذاتى \% & 6 \\
\hline
\end{tabular}

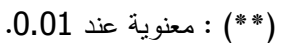
حيث أن : y: نتشير إلى القيمة الثقيرية للإنتاج العالمى و المعروض العالمى و انتاج واستهلاك وواردات مصر من الزيوت النباتية ونسبة الاكتفاء الذاتى منها

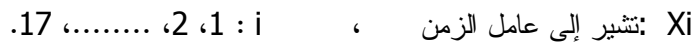


- تطور الأسعار المحلية والعالمية وسعر الاستيراد للزيوت النباتية 1- تطور السعر المحلى للزيوت النباتية

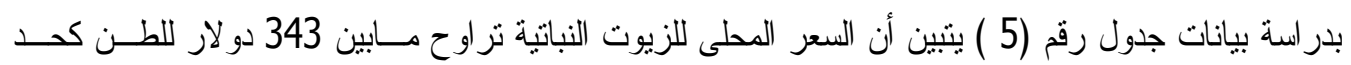

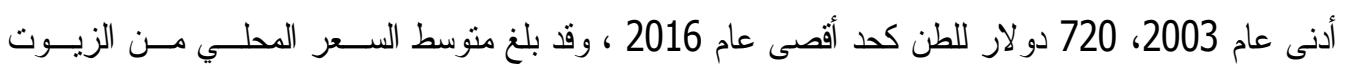

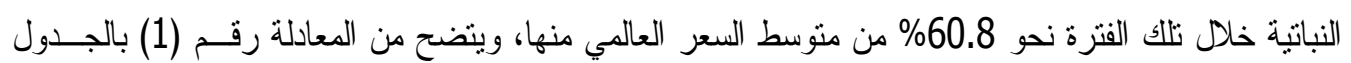

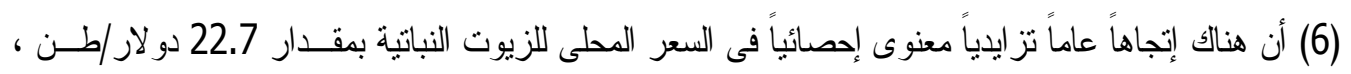

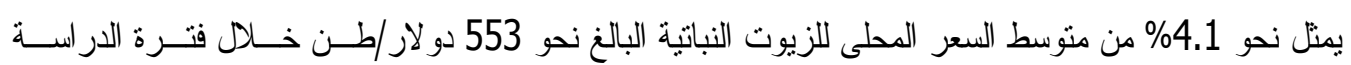

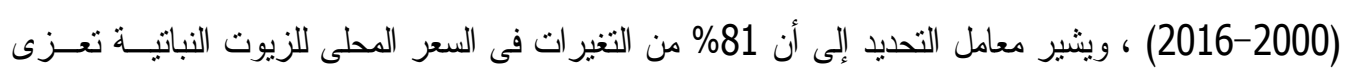

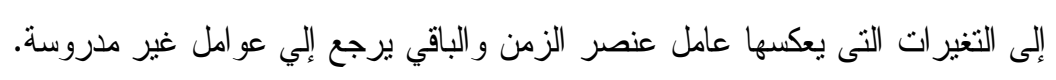
2- تطور السعر العالمى للزيوت النباتية . يوضح بيانات الجدول رقم (5 ) أن السعر العالمى للزيوت النباتية تراوح مابين 508 دو لار /طن كحد أدنى عـام النهام

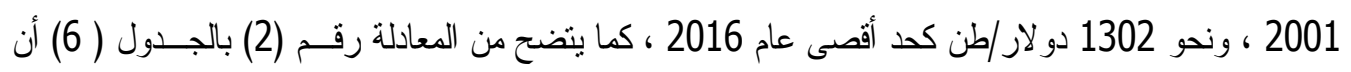

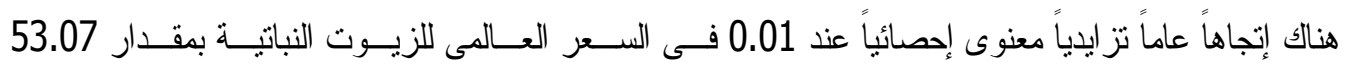

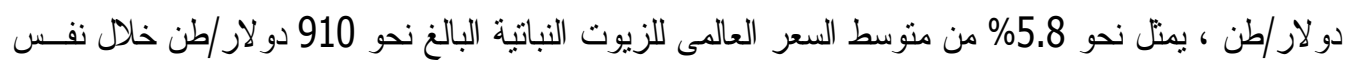

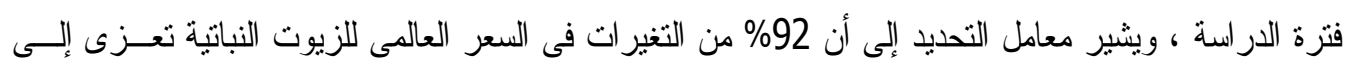

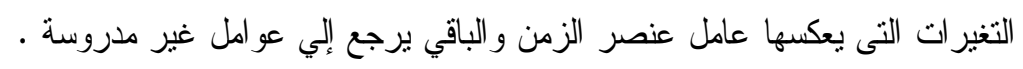
جدول رقم (5) : تطور السعر المحلى والعالمى والاستيراد للزيوت النباتئية

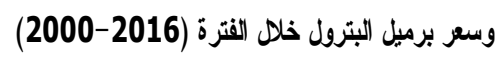

القيمة: بالدولار

\begin{tabular}{|c|c|c|c|c|c|c|}
\hline \multirow{2}{*}{ 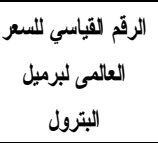 } & \multirow{2}{*}{ السعر العالمى لبرميل } & \multicolumn{4}{|c|}{ الزيوت النباتية } & \multirow{2}{*}{ البيان } \\
\hline & & سعر الاستيراد & \% لللسع المحلي من & السعر العالمى & السعر المحلى & \\
\hline 100 & 53 & 797 & 85.56 & 547 & 468 & 2000 \\
\hline 86.79 & 46 & 673 & 88.98 & 508 & 452 & 2001 \\
\hline 88.68 & 47 & 688 & 74.05 & 551 & 408 & 2002 \\
\hline 101.9 & 54 & 616 & 54.79 & 626 & 343 & 2003 \\
\hline 134.0 & 71 & 1031 & 51.74 & 717 & 371 & 2004 \\
\hline 188.7 & 100 & 964 & 61.43 & 700 & 430 & 2005 \\
\hline 228.3 & 121 & 933 & 65.71 & 694 & 456 & 2006 \\
\hline 252.8 & 134 & 1102 & 62.56 & 860 & 538 & 2007 \\
\hline 343.4 & 182 & 1114 & 50.86 & 1166 & 593 & 2008 \\
\hline 218.9 & 116 & 3310 & 74.07 & 910 & 674 & 2009 \\
\hline 281.1 & 149 & 1842 & 61.49 & 979 & 602 & 2010 \\
\hline 179.2 & 95 & 2166 & 57.91 & 1081 & 626 & 2011 \\
\hline 141.5 & 75 & 2329 & 57.22 & 1136 & 650 & 2012 \\
\hline 128.3 & 68 & 2492 & 56.51 & 1191 & 673 & 2013 \\
\hline 132.1 & 70 & 2655 & 55.94 & 1246 & 697 & 2014 \\
\hline 141.5 & 75 & 2663 & 55.93 & 1248 & 698 & 2015 \\
\hline 113.2 & 60 & 2817 & 55.3 & 1302 & 720 & 2016 \\
\hline 168.3 & 89 & 1658 & 60.77 & 910 & 553 & المتوسط \\
\hline
\end{tabular}

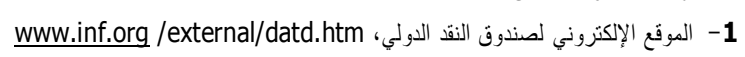

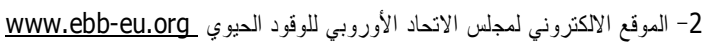


بدر اسة بيانات الجدول رقم (5 ) يتضح أن سعر الاستير اد للزيوت النباتية بنز اوح مابين نحــو 616

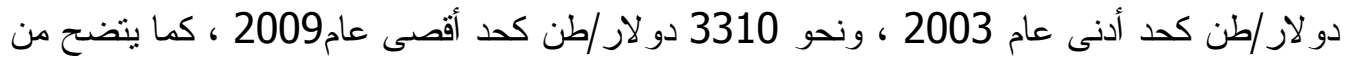

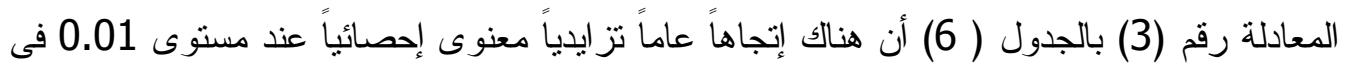

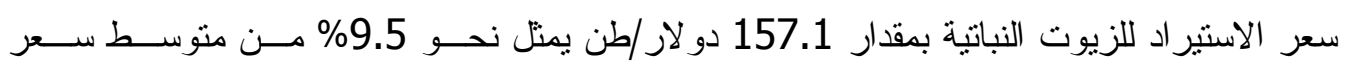

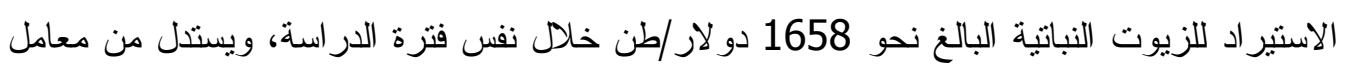

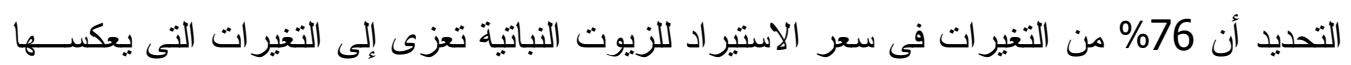

$$
\text { 4- عامل عنصر الزمن و الباقي يرجع إلي عو امل غير مدروسة. }
$$

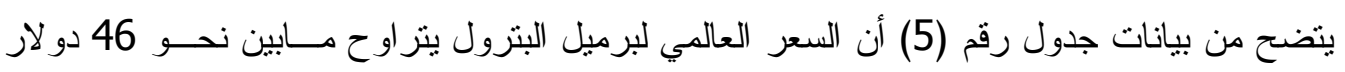

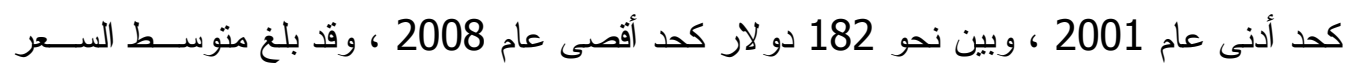

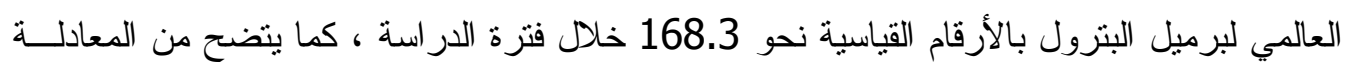

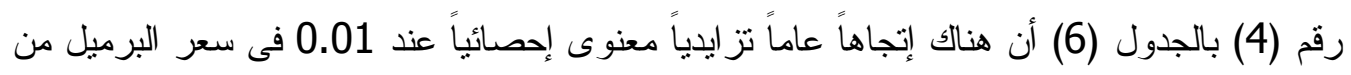
البترول بمقدار 1.23 دو لار للبرميل ، يمثل نحو 1.4\% من متوسط سعر برميل البترول البالغ نحو

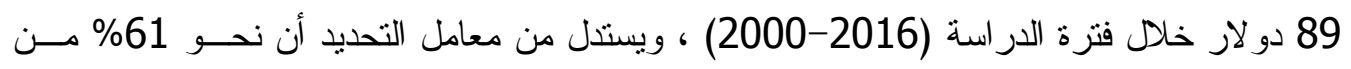

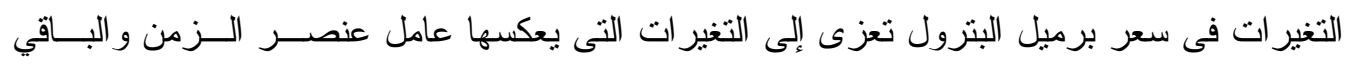
يرجع إلي عو امل غير مقيسه.

جدول رقم (6) : معادلات الاججاه العام لتطور السعر المحلى والعالمى والاستيراد للزيوت النباتية

\begin{tabular}{|c|c|c|c|c|c|}
\hline $\mathbf{R}^{2}$ & معدل التغير & متوسط الفترة & المعادلة & 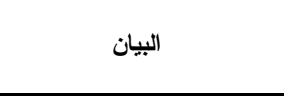 & رقم - - مق \\
\hline 0.814 & 4.1 & 553 & $\begin{array}{l}\hat{y}=348.75+22.68 X_{i} \\
(8.101)^{* *}\end{array}$ & السعر المحلى للزيوت النباتية & 1 \\
\hline 0.924 & 5.8 & 910 & $\begin{array}{l}\hat{y}=431.67+53.07 X_{i} \\
(13.504)^{* *}\end{array}$ & السعر العالمى للزيوت النباتية & 2 \\
\hline 0.760 & 9.5 & 1658 & $\begin{array}{l}\hat{y}=244.47+157.10 X_{i} \\
(6.883)^{* *}\end{array}$ & سعر الاستيراد للزيوت النباتية & 3 \\
\hline 0.606 & 1.4 & 89 & $\begin{array}{l}\hat{y}=0.52+25.71 X_{i}-1.36 \\
X^{2}{ }_{i} \\
(4.640)^{* *}(-4.544)^{* *}\end{array}$ & السعر العالمي لبرميل البترول & 4 \\
\hline
\end{tabular}

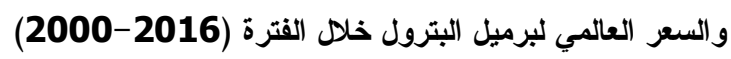

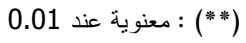

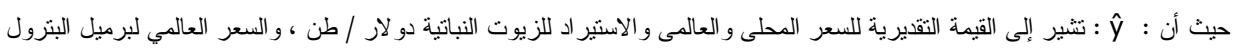


- الآثار الإقتصادية لإنتاج الديزل الحيوى العالمى على أسعار الواردات المصـرية مـن الزيــوت

1- أثز السعر العالمى لبرميل البترول على الكمية المنتجة من الديزل الحيوى العالمى

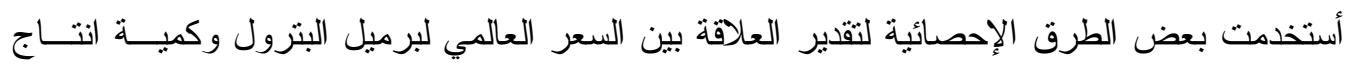

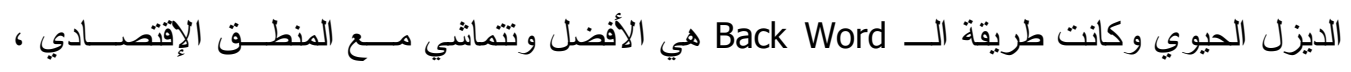

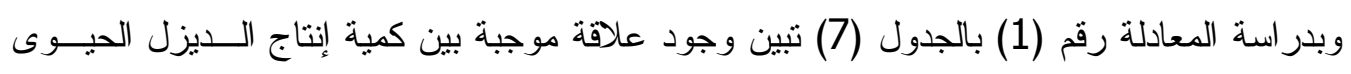

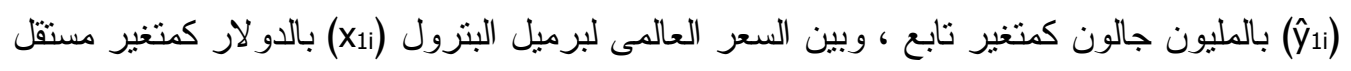

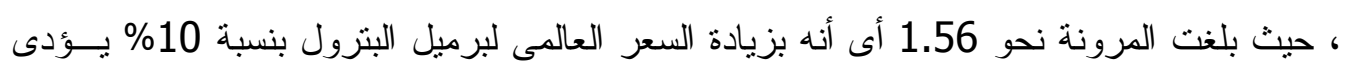

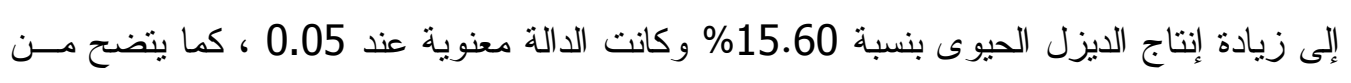

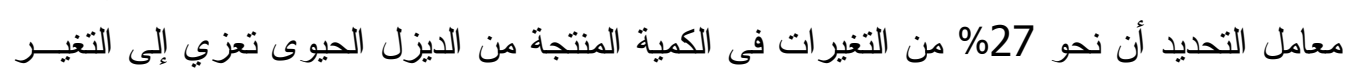

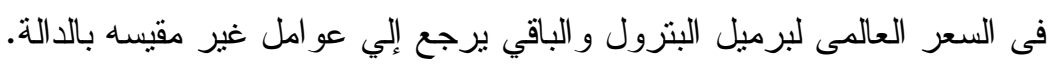
2- أثز بعض العوامل لإنتاج الديزل الحيوى على السعر العالمى للزيوت النباتية

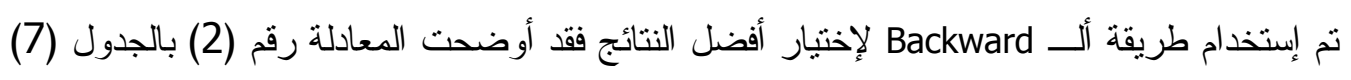

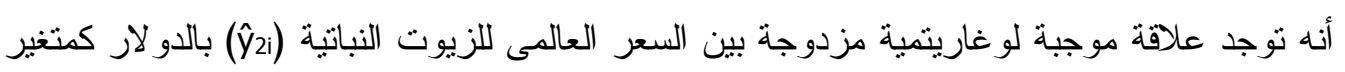

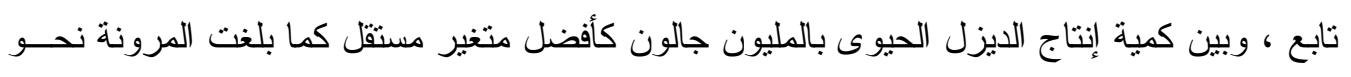

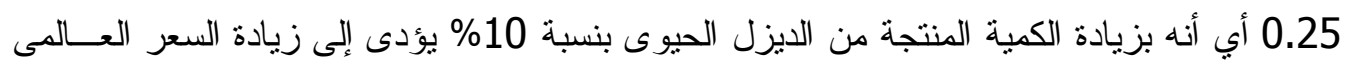

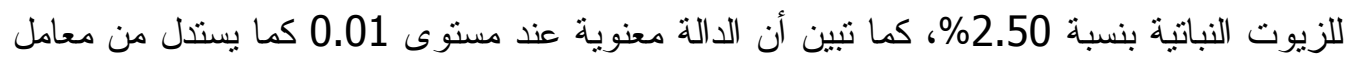
التحديد أن 92\% من التغيرات فى السعر العالمى للزيوت النباتية تعزى إلى التغير فى الكية المنتجة من الديزل الحيوى و الباقي برجع إلي عو امل غير مقيسه بالدير بالدالة. 3- أثر كمية الإتتاج العالمى للايزل الحيوى على سعر إستير اد مصر للزيوت النباتية

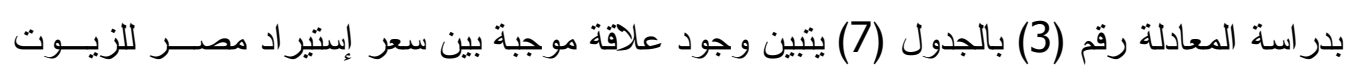

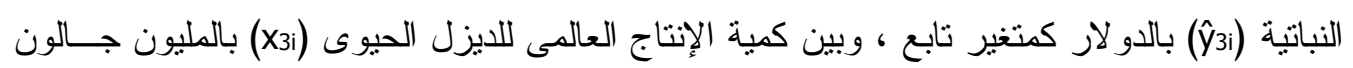

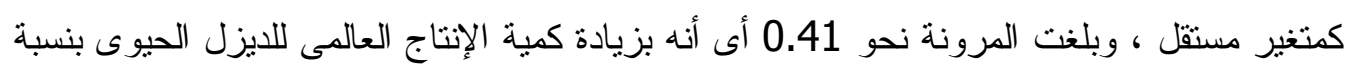

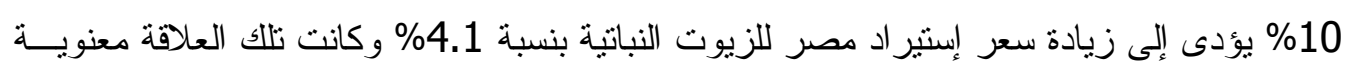

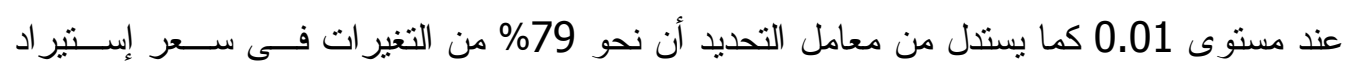

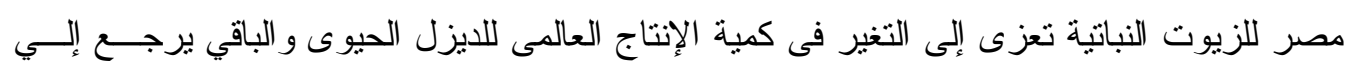
عو امل غير مقيسه بالدالة . مئل 
جدول (7): تقدير العلاقات الإقتصادية لكل من إنتاج الايزل الحيوى و السعر العالمى للزيوت النباتية وسعر إستيراد مصر منها

خلا فترة الاراسة (2000- 2016 )

\begin{tabular}{|c|c|c|c|c|}
\hline $\mathbf{F}$ & $\mathbf{R}^{2}$ & المعادلة & البيان & رقم المعادلة \\
\hline$* 5.40$ & 0.265 & $\begin{array}{l}L \hat{y}_{1 i}=0.32+1.56 L X_{i} \\
(2.324)^{*}\end{array}$ & كبرمية إنتاج الديزل الحيوي علي السعر العالمي & 1 \\
\hline **173.98 & 0.921 & $\begin{array}{l}L \hat{y}_{2 i}=2.12+0.25 L X_{i} \\
(13.190)^{* *}\end{array}$ & الديزل العيوي العالمي للزيوت النباتية علي كمية إنتاج & 2 \\
\hline$* * 54.64$ & 0.785 & $\begin{array}{l}L \hat{y}_{3 i}=1.80+0.41 \mathrm{LXi} \\
(7.392)^{* *}\end{array}$ & 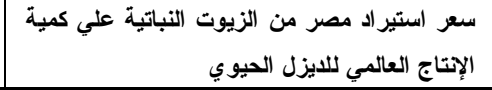 & 3 \\
\hline & & \multicolumn{2}{|c|}{ (**** ) : معنوية عند 0.01.} & (") : معنوية عند \\
\hline & & & & حيث أن : \\
\hline & & & \multirow{6}{*}{\multicolumn{2}{|c|}{ 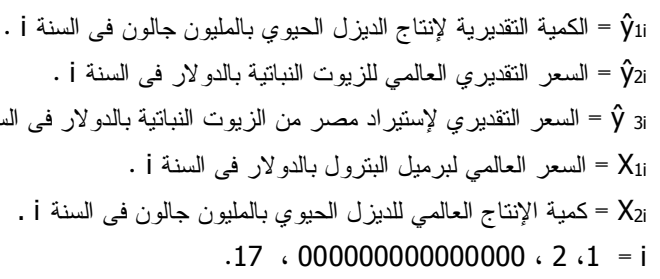 }} \\
\hline & & & & \\
\hline & & & & \\
\hline & & & & \\
\hline & & & & \\
\hline & & & & \\
\hline & & & \multicolumn{2}{|c|}{. log = L لو غاريتم = لو } \\
\hline & & & \multicolumn{2}{|c|}{ المصدر : حسبت من جدولي أرقام (3 ، 5) بالدر سة. } \\
\hline
\end{tabular}

- أهم العوامل المؤثرة على الواردات المصرية من الزيوت النباتية :

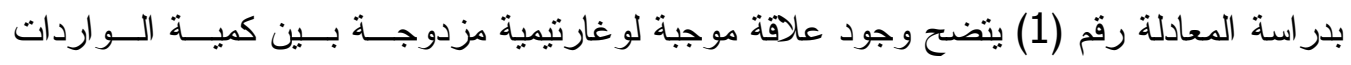

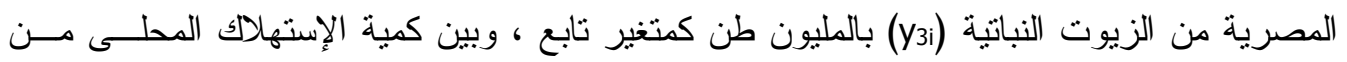

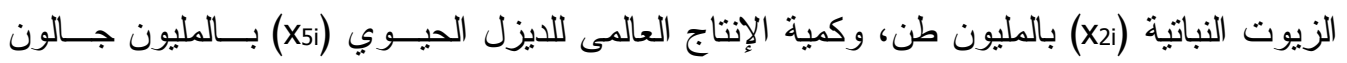
كمتغير ات مفسرة و الموضحة كالتالي :

(1) $L \hat{y}_{1 i}=-1.95+0.79 L X_{2 i}+0.50 L X_{5 i}$

$$
\begin{array}{rr} 
& (2.959) * \quad(3.840) * * \\
\mathbf{R}^{2}=0.955 \quad \mathbf{F}=148.146 * * \\
: \text { حيث أن }
\end{array}
$$

القيمة التقديرية لكمية و اردات مصر من الزيوت النباتية بالمليون طن فى السنةز.

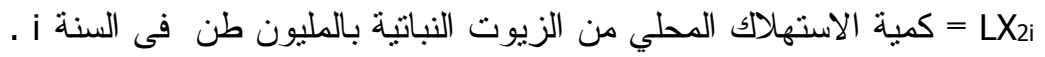

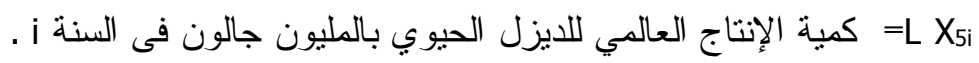

$$
\begin{aligned}
& \text {. } 000000 \text { ، } 2 \text { ، } 2 \text { = } \mathrm{i} \\
& \text { - لو غاريتم = log = L }
\end{aligned}
$$


و أتضح أنه بزيادة كمية الاستهلاك المحلى من الزيوت النباتية بنسبة 10\% يؤدى إلى زيادة

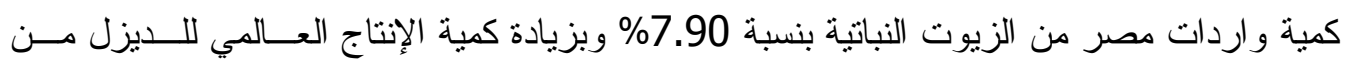

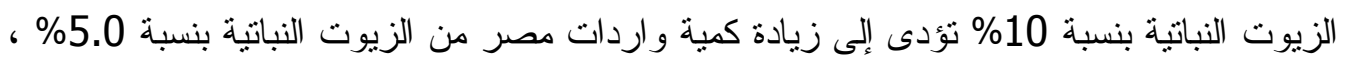

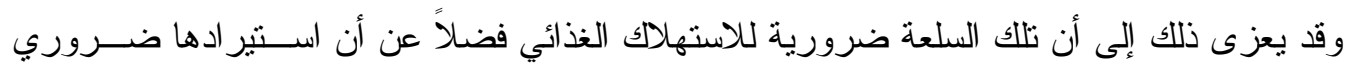

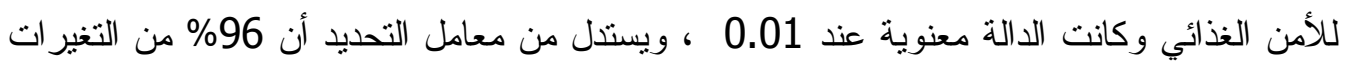

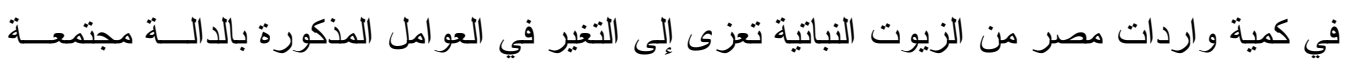
و الباقي يرجع إلي عوامل غير مقيسه بالدالة.

\section{الملخص}

يعرف الوقود الحيوي بأنه الطاقة المستمدة من لكائنات الحية سو اء النبانية أو الحيو انية ، ويستهلك إنتاج الوقود الحيوي نحو 9\% من الكمية المنتجة من الزيوت النباتية لإنتاج الديزل الحيوي و التي من المتوقع بن أن ترتفع إلى 20 \% بحلول عام 2018، وأن 2\% من إجمالي مساحة المحاصيل في العالم التى تستخدم في

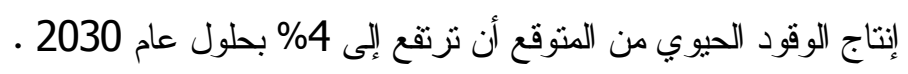

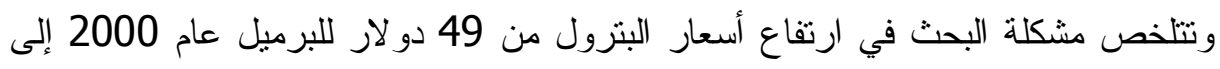

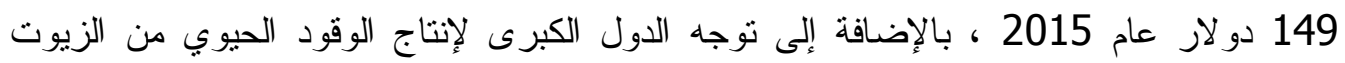

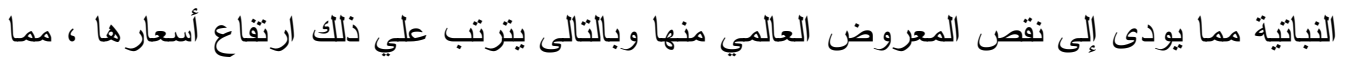
يؤثر سلباً على الدول المستورة لمحاصيل الزيوت ومنها مصر مما بتسبب في ارتفاع أسعار محاصيل الزيوت النباتية و انخفاض نسبة الإكتفاء الذاتي .

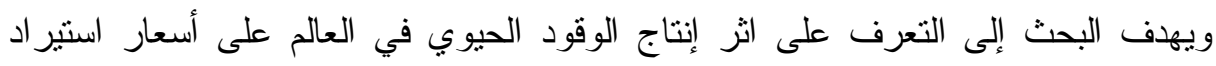

مصر اللسلع الغذائية الاستير اتيجية من الزيوت النباتية .

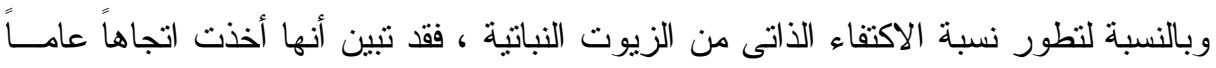

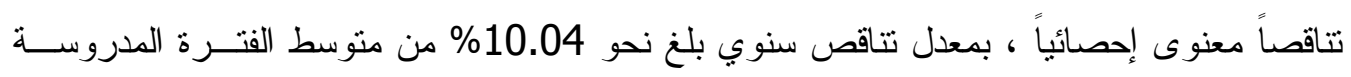

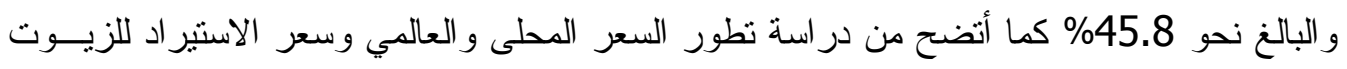
النباتية أنها أخذت اتجاها عاما تز ايدياً معنوى إحصائيا بمعدل تغير سنوي بلغ نحر ندو

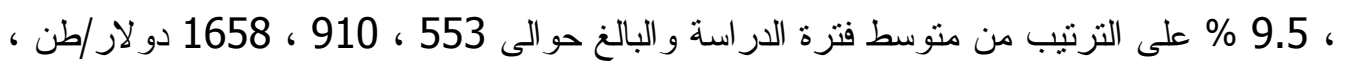

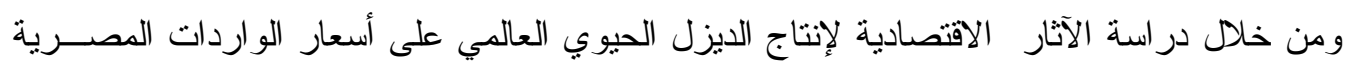

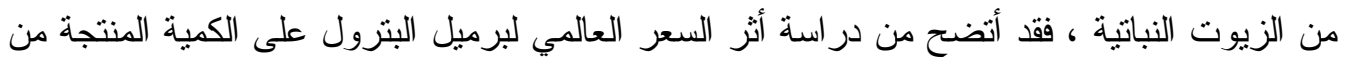

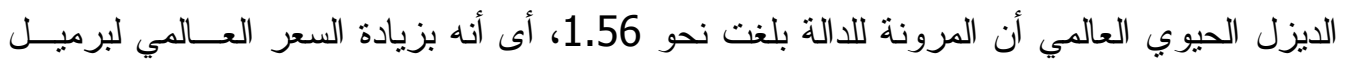
البترول بنسبة 10\% سوف يؤدى إلى زيادة إنتاج الديزل الحيوي بنسبة 15.60\% ، أمئه أما بالنسبة لأثر

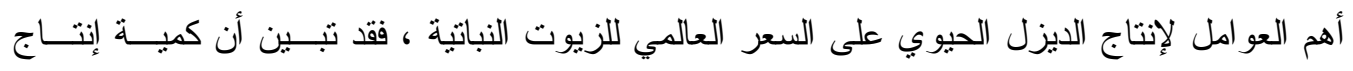

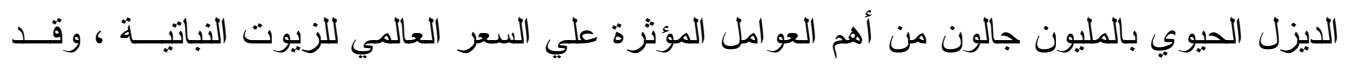

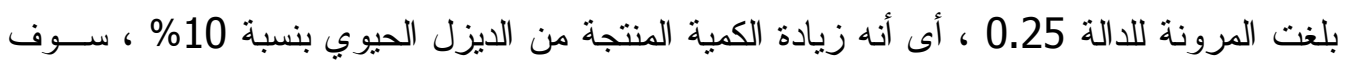

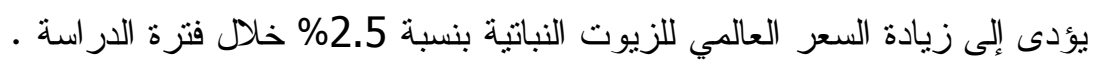


وبدر اسة أثز كمية الإنتاج العالمي للديزل الحيوي على سعر استنير اد مصر مــن الزيــوت النباتية ، تبين أن المرونة الإجمالية للدالة بلغ نحو 0.41 ، أى أنه بزيادة كمية الإنتاج العالمي للديزل

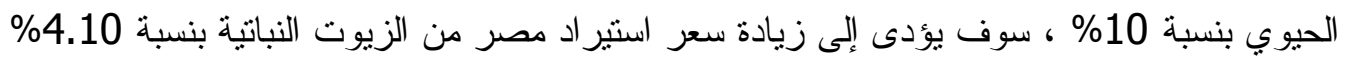

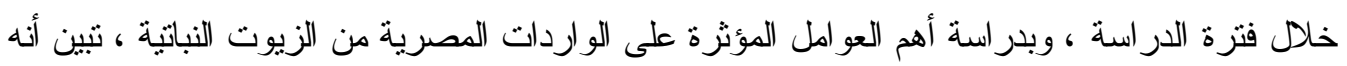

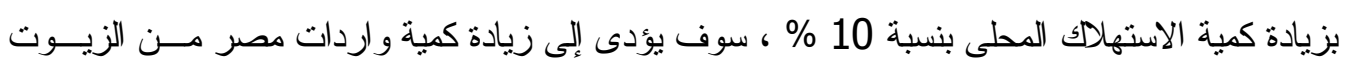

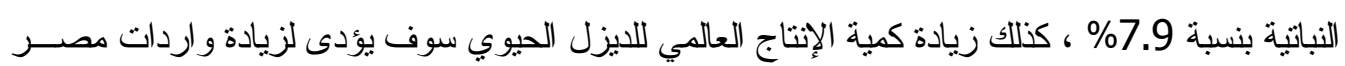

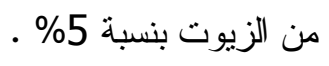

\section{التوصيات}

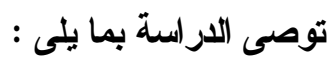

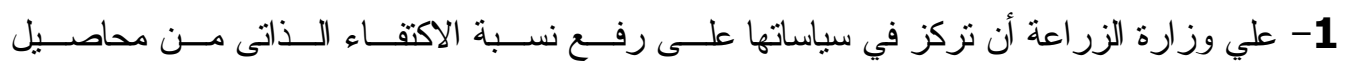

$$
\text { الزيوت النباتية. }
$$

2- العمل علي نتويع مصادر أسواق الاستير اد لمحاصيل الزيوت النباتية من خلال دراسة الأسواق العالمية لتشجيع المز ارعين علي زر اعة المحاصيل الزينية. 3- در اسة رفع السعر المحلى للطن من المحاصيل الزينية لمو اجهة الزيادة العالمية.

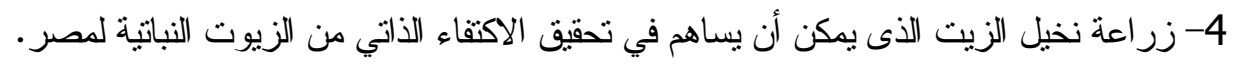

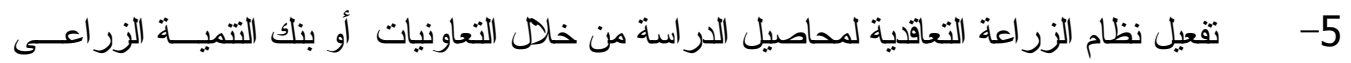
حتى يضمن للمز ارع تسويق محاصيله .

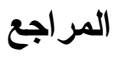

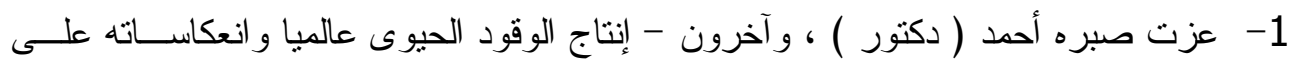

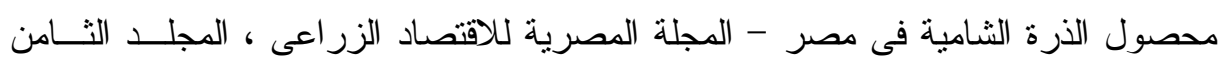

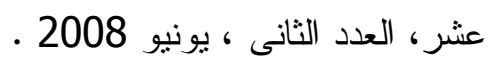

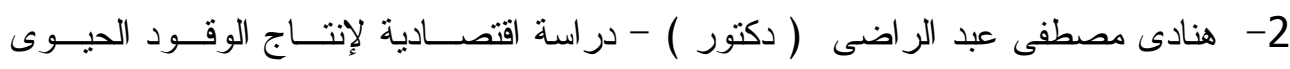

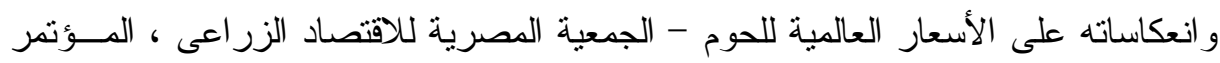

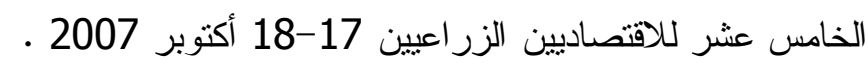

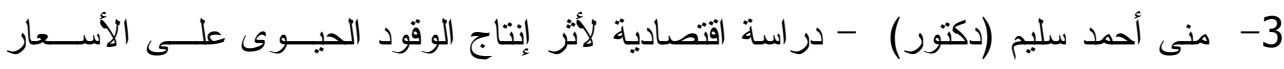

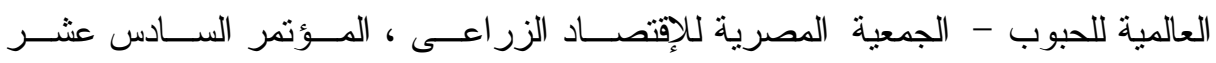
للاقتصاديين 15-16 أكتوبر 2008

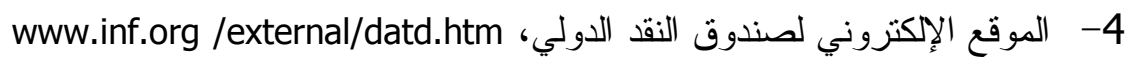
5- الموقع الالكتروني لمجلس الاتحاد الأوروبي للوقود الحيوي www.ebb-eu.org

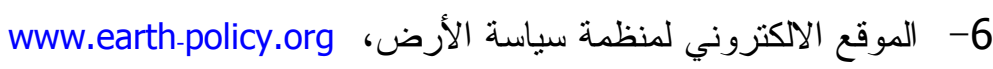

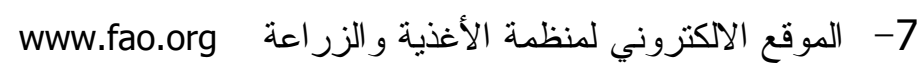

